\title{
Message from the new President
}

\author{
Hiroshi Satoh
}

Published online: 30 June 2009

(C) The Japanese Society for Hygiene 2009

It is a great honor to be elected as the President of the Japanese Society for Hygiene for the new triennium beginning April 2009. After being chosen as the President at the 79th General Assembly of the society held in Tokyo at the end of March, I have been feeling a heavy responsibility.

Taking advantage of this opportunity, I would like to remind you of the history of the society. It goes back to the first meeting of the Japanese Association of Medical Sciences held in 1902. Our society was one of the 16 affiliated specialist medical societies. Since the Japanese Association of Medical Sciences held a meeting every 4 years, our society decided in 1926 to hold an annual meeting for the advancement and promotion of the sciences in the field. At that time, annual meetings were held together with the Societies for Bacteriology and Parasitology, but soon exclusively for our society. Thus, our annual meeting has been held continuously since then, and the 80th one will be held next year (2010).

Recently the society has developed and expanded its activities because of the leadership and endeavors of the successive boards of directors and the various committees. Since our English-language journal, Environmental Health and Preventive Medicine (EHPM), now appears in PubMed, we look forward to EHPM being included in MEDLINE as well. Inclusion in MEDLINE has been a long-cherished desire. A grant for publication of scientific research results, one of the Grants-in-Aid for Scientific Research from the Japan Society for the Promotion of Science, to EHPM has been received after 2 years absence. This is because of the growing internationalization of EHPM's authorship and circulation. Owing to the strong

H. Satoh $(\square)$

Tohoku University Graduate School of Medicine, Sendai, Japan

e-mail: h.satoh@ehs.med.tohoku.ac.jp driving force of former president Professor K. Morimoto, the number of allied research project teams in which our members perform specific research work in cooperation with the members of other related academic and professional societies is now more than 20 .

There are, however, several problems that need to be solved by the society. Although efforts have been made to stimulate members of the younger generation, for example, by giving various awards, the outcome is as yet insufficient. The publisher of EHPM has been changed to Springer Japan and we have been enjoying benefits such as a larger circulation. However, the increased expense of publishing the journal is a matter of concern. Since laws concerning public-service corporation reforms were passed at the end of last year (2008), it is necessary to discuss the characteristics of the organization and its corporate status.

As we have not had a board meeting yet, the abovementioned problems to be solved are just considerations in my mind, and future discussions among the board of directors and in the general assembly about various issues will be required.

As mentioned above, the upcoming 80th annual meeting will be held in Sendai, and I was appointed to be the organizer of the meeting. Therefore, two secretariats were simultaneously established for the society and the annual meeting, and the situation in our laboratory is still a bit disorganized. I hope that it will be under control by the time this message appears in the journal.

Finally, I would like to express my intention to promote the development of the society for more glorious achievements in the future, proceeding together with every member.

Hiroshi SATOH

President of the Society

Professor, Tohoku University Graduate School of Medicine 